\title{
Establishment of Index System of Commercial Banks' Post-Evaluation of Loan Project Based on the AHP
}

\author{
Xiao-rong $\mathrm{Du}^{1}$, Xiao-yue $\mathrm{Fu}^{2}$, and Ling-xue $\mathrm{Zhang}^{3}$ \\ ${ }^{1)}$ Business School of Hohai University, Nanjing, Jiangsu, China \\ ${ }^{2)}$ Business School of Hohai University, Nanjing, Jiangsu, China \\ ${ }^{3)}$ Business School of Hohai University, Nanjing, Jiangsu, China
}

\begin{abstract}
In recent years, as commercial banks' non-performing loans continue to rise, commercial banks have paid increasing attention to post-evaluation of loan project. This paper is based on the concept of social responsibility and draw lessons from the existing literature results, then designs an index system of post-evaluation of loan project from six aspects, and by using AHP to determine the weight of various indicators in order to comprehensively and systematically reflect problems of commercial banks' credit management, to promote the decision-making and management level of credit departments, and to improve the quality of loans. At the same time, promoting commercial banks to enhance the social sense of responsibility and consciously maintain the sustainable development of society and the environment.
\end{abstract}

Keywords - Commercial Banks, Post-Evaluation of Loan Project, Index System, AHP

\section{基于 AHP 的商业银行贷款项目后评价指标体系构建}

\author{
杜晓荣 付晓月 张羚雪 \\ 河海大学商学院, 南京, 江苏, 中国
}

摘 要 近年来,随着商业银行不良贷款规模持续攀升, 商业银行对贷款项目后评价的工作日益重视。本文基于社会责任理念, 借鉴 已有的文献成果, 从六个方面设计了商业银行贷款项目后评价指标体系, 并运用层次分析法确定了各级指标权重, 以全面、系统地反 映商业银行贷款管理中的问题, 提升信贷决策和管理水平, 提高贷款质量。同时, 也促进商业银行增强社会责任感, 自觉维护社会与 环境的可持续发展。

关键词 商业银行，贷款项目后评价，指标体系，层次分析法（AHP）

\section{1. 引言}

纵观席卷全球的金融海啸, 其最直接的源头是美国的 次贷危机。奥巴马曾在国际金融危机一周年祭演讲中提出 “由于整个华尔街、整个华盛顿责任的集体缺失, 造成了全 球金融系统的崩溃, 要想避免“灾难”的再次发生, 商业银行 应当回归责任本质”。

商业银行的社会责任是指银行业金融机构对其股东、 员工、消费者、商业伙伴、政府和社区等利益相关者以及
为促进社会与环境可持续发展所应承担的经济、法律、道 德与慈善责任。越来越多的国外商业银行将社会责任列为 银行的战略目标之一。“赤道原则”是根据世界银行和国际 金融公司的有关环保指导方针确立的，采纳这一原则的银 行必须承诺其贷款只能投向那些能够满足环境保护要求的 发展项目，项目借款人必须通过有关环保评估才能获得贷 款, 目前已有近百家国外知名银行在信贷活动中遵循这一 原则。我国银行业的社会责任意识也在逐渐增强, 2012 年, 
银监会出台《绿色信贷指引》, 指出银行金融业必须通过绿 色信贷的发放, 达到保护和改善生态环境、提高资源利用 效率和有效承担社会责任的效果。各商业银行也在不断加 大对公益性产业的金融扶持力度。

近年来, 中国银行业的资产和负债规模稳步增长, 增 幅均在 $13 \%$ 以上, 而银行业信用风险也在持续增加。2013 年上半年, 我国商业银行的不良贷款率为 $1.04 \%$, 同比增 长 $22 \%, 2014$ 年末商业银行不良贷款余额为 8426 亿元, 较 年初增加 2506 亿元。面对日益复杂的竞争环境, 加强信贷 风险管理已成为我国商业银行信贷管理中首要的问题。国 际金融组织和发达国家早就将贷款项目后评价理论运用于 信贷管理中。目前, 世界银行已经形成一套完整的后评价 制度方法及工作程序, 并对贷款项目的社会效益及环境效 益评价做出明确规定。我国商业银行对贷款项目后评价的 相关政策规定及学术研究成果也在逐渐增多。中国建设银 行在《中国建设银行贷款项目后评价实施办法 (试行)》中 明确规定了贷款项目后评价的指标体系及内容, 其中以经 济、财务性指标为主。中国银行也明确规定了贷款项目后 评价的程序及制度。王红平 (2003)、刘斌 (2004) 研究认 为贷款项目后评价应重点关注项目的财务效益。然而已有 的评价体系并不能很好地体现商业银行贷款的社会责任效 果, 可能会忽视银行业因只顾追求自身利益的最大化而盲 目投放贷款的问题, 进而也可能会忽视由此引发的社会风 险及生态危机等问题。

基于此, 本文将在已有的贷款项目后评价文献成果基 础上, 增加有关社会及环境效益的评价内容, 一方面有利 于全面评价贷款项目的效益、提高贷款质量; 另一方面也 有利于增强银行的社会责任感, 促进社会与环境的可持续 发展。

\section{2. 商业银行贷款项目后评价的目标}

\section{1 总目标}

通过对商业银行贷款项目的后评价, 全面总结经验和 教训, 针对贷款管理中存在的问题, 提出相应的措施和建 议, 以保证银行贷款质量, 提高银行信贷部门的决策和管 理水平。

\section{2 分项目标}

通过“项目建设及运营评价”，判断项目工期保证情况、 单位生产能力投资额情况等, 以进一步提高项目施工管理 质量以及对投入资金的使用效果等。

通过“项目财务效益评价”, 判断该项目涉及的主要财 务指标是否与预期相偏离, 是否对银行及时收回贷款造成
影响, 以进一步提高商业银业行对项目财务活动的监督能 力。

通过“项目生态效益评价”, 判断该项目对项目区周边 生态环境的影响、对自然资源的使用及保护情况。

通过“项目社会效益评价”, 判断该项目对周边居民物 质及文化生活质量带来的影响、对拉动就业及造福社会公 众等方面的积极效用。

通过“借款人资信状况评价”，评价借款人资产负债率、 流动比率、速动比率等财务指标, 以进一步了解借款人的 资信状况, 有效衡量银行的信贷风险质量。

通过“贷款使用及收回评价”，评价贷款的偿还率、利 息实收率等, 以估算出贷款收回的可能性和利息收益, 直 接反映出该项银行贷款的质量。

\section{3. 商业银行贷款项目后评价递阶层次结构模型指标 体系的构建}

依据科学性、可比性及全面性原则, 在广泛调查收集 和参考相关文献的基础上，借鉴世行、亚行及建行对贷款 项目后评价的相关规定, 构建我国商业银行贷款项目后评 价的指标体系 (如下图所示), 其中目标层指标 1 个, 准则 层指标 6 个, 指标层指标 16 个。

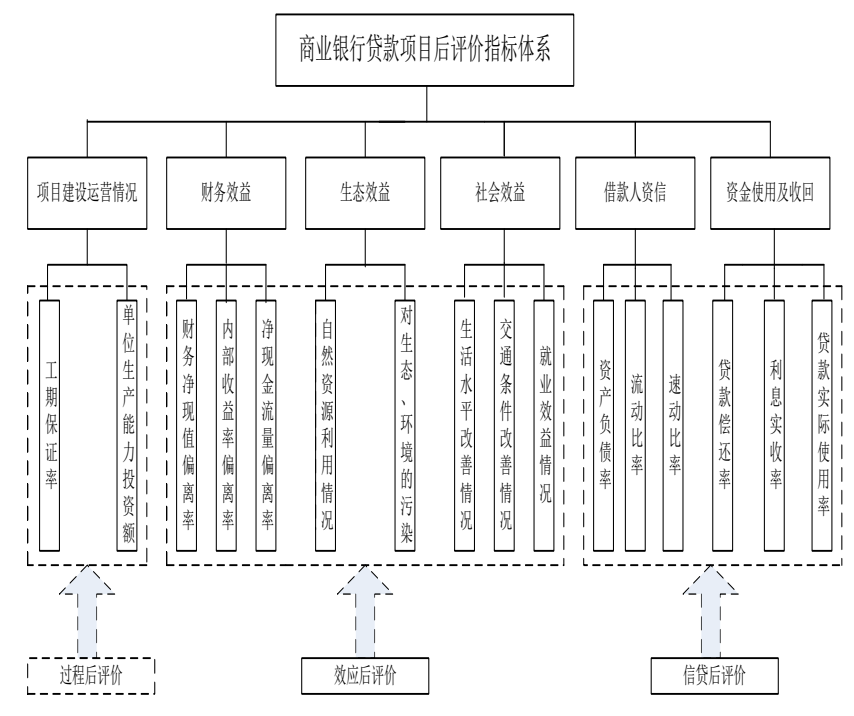

图 1 商业银行贷款项目后评价递阶层次结构模型指标体系

\section{4. 基于 AHP 的商业银行贷款项目后评价指标权重的 确立}

运用上图所列示的指标体系, 应用 AHP 法对指标进行 赋权。首先, 将总评价目标分解成多级指标, 然后对同一 层的指标进行两两比较, 按照 1-9 比率标度法判断其重要程 度的不同, 将差异转换为定量数值, 形成判断矩阵。其次, 
对判断矩阵 $\mathrm{A}$, 计算满足 $\mathrm{AW}=\lambda_{\text {max }} \mathrm{W}$ 的特征根和特征向量, 并将特征向量正规化后得到 $\mathrm{W}=\left[\mathrm{W}_{1}, \mathrm{~W}_{2}, \ldots \mathrm{W}_{\mathrm{n}}\right]^{\mathrm{T}}$ 来作为本层 次元素对于其隶属指标的权重。而为了保证不同层次指标 的重要性程度相一致, 引入 CI 度量矩阵偏离程度, 即判断 矩阵 $\mathrm{A}$ 的最大特征根 $\lambda_{\text {max }}$ 与 $\mathrm{n}$ 之间的差额和 $\mathrm{n}-1$ 的比。通常 判断矩阵的阶数越大, 检验难度越高, 通过查找平均随机 一致性指标 RI, 计算一致性比率 CR 作为检验指标, 其中, $\mathrm{CR}=\mathrm{CI} / \mathrm{RI}$ 。若 $\mathrm{CR}<0.10$, 则表明检验结果具有一致性, 判 断矩阵是可以接受的; 否则必须重新进行指标重要性比较, 调整判断矩阵中的元素, 直到具有满意的一致性为止。指 标名称及权重见下表。

从下表可以看出, 权重排在前三位的指标分别为: 净 现金流量偏离率 $(0.181)$ 、速动比率 $(0.178)$ 和贷款偿还率 (0.120), 这符合当前商业银行贷款项目后评价的实际情况, 较高的净现金流量及速动比率是确保银行贷款质量的重要 条件, 而贷款偿还率则直接反映出贷款的收回情况。同时, 生活水平改善情况、对生态、环境污染的指标权重分别为 0.103 和 0.100 , 在该指标体系中的地位也较为重要, 这反 映出商业银行经营理念的变革, 在重视经济效益的同时, 力求社会及生态效益的实现。

\section{5. 结语}

本文针对商业银行贷款管理中存在的问题, 构建了一 套多目标的贷款项目后评价指标体系, 其中不仅包括经济 性指标, 还包含了社会及环境性指标的内容, 并运用层次 分析法确定各级指标权重。该体系不仅可以弥补当今商业 银行贷款后评价普遍忽视对社会和环境评价的不足, 完善 贷款项目后评估指标体系的内容, 还有助于提升我国商业 银行贷款决策水平和贷款质量。

表 1 商业银行贷款项目后评价指标名称及权重排名表

\begin{tabular}{|c|c|c|c|c|c|}
\hline 排名 & 指标 & 权重 & 排名 & 指标 & 权重 \\
\hline 1 & $\begin{array}{c}\text { 净现金流量 } \\
\text { 偏离率 }\end{array}$ & 0.181 & 9 & 贷款实际使用率 & 0.022 \\
\hline 2 & 速动比率 & 0.178 & 10 & 工期保证率 & 0.020 \\
\hline 3 & 贷款偿还率 & 0.120 & 11 & 单位生产能力投资额 & 0.010 \\
\hline 4 & $\begin{array}{c}\text { 内部收益率 } \\
\text { 偏离率 }\end{array}$ & 0.108 & 12 & 流动比率 & 0.008 \\
\hline 5 & 利息实收率 & 0.107 & 13 & 财务净现值偏离率 & 0.004 \\
\hline 6 & $\begin{array}{c}\text { 生活水平改 } \\
\text { 善情况 }\end{array}$ & 0.103 & 14 & 就业效益情况 & 0.003 \\
\hline 7 & $\begin{array}{c}\text { 对生态、环 } \\
\text { 境的污染 }\end{array}$ & 0.100 & 15 & 交通条件改善情况 & 0.002 \\
\hline 8 & 资产负债率 & 0.033 & 16 & 自然资源利用情况 & 0.001 \\
\hline
\end{tabular}

\section{参考文献(References)}

[1] Kamal Gueye. Financing Sustainable Development: Trends and Emerging Policy Approaches in Asia and the Pacific. International Review for Environmental Strategies, Vol.3, No.1, pp.153-163,2002.

[2] Mustafa Yurdakul and Ergun Eraslan. Development of a component-based machining centre selection model using AHP. International Journal of Production Research,Vol.50, No.22, pp.6489-6498, 2012,

[3] Jingxia Li, Fang Hu, and Zhihua Liu. A new commercial bank loan project performance evaluation model. Journal of Hunan University: natural science edition, 2010,37(2): 83-87.

[4] Hongping Wang. Discussion of post-evaluation of loan project. Economists. 2003, (5): 278-278.

[5] Bin Liu. After the national development bank loan project evaluation system and enlightenment. The financial theory and practice, 2004(7): 91-92. 